\title{
Tensile Strength and Microscopic Adhesion Observation of Dental Composite Restorative Material Manufactured From Sisal Nanofiber as Filler
}

\author{
Dwi Aji Nugroho ${ }^{1, *}$ Widjijono ${ }^{2}$ Nuryono $^{3}$ Widya Asmara ${ }^{4}$ Aulia Rahmasari ${ }^{5}$ Ensa Dyota $^{5}$
}

${ }^{1}$ Department of Biomaterial, School of Dentistry, Faculty of Medical and Health Science, Universitas Muhammadiyah Yogyakarta, Yogyakarta, Indonesia

${ }^{2}$ Department of Biomaterial, Faculty of Dentistry, Universitas Gadjah Mada, Yogyakarta, Indonesia

${ }^{3}$ Department of Chemistry, Faculty of Mathematics and Natural Science, Universitas Gadjah Mada, Yogyakarta, Indonesia

${ }^{4}$ Department of Microbiology, Faculty of Veterinary, Universitas Gadjah Mada, Yogyakarta, Indonesia

${ }^{5}$ School of Dentistry, Faculty of Medical and Health Science, Universitas Muhammadiyah Yogyakarta

Yogyakarta, Indonesia

*Corresponding author. Email: dwiajinugrohodrg@gmail.com

\begin{abstract}
Background: Dental Composite consists of inorganic filler material that does not have chemical adhesion to organic materials. Tooth structure and adhesive materials contained many organic materials. Inorganic fillers could be substituted by organic material. This material was sisal fiber. These fibers were hard and used as mechanical amplifiers to the matrix resin. This study manufactured dental composite with sisal nanofibers as the filler. Objective: This study investigated the microscopic adhesion between dental composite made from sisal nanofibers to tooth structure which was tested by tensile strength. Materials and Methods: Sisal fiber was converted into nano-sized. It was mixed with BisGMA (Sigma Aldrich), UDMA (Sigma Aldrich), TEGDMA (Sigma Aldrich), Champhorquinone (Sigma Aldrich). Composite Z350 XT (3M ESPE) was utilized as control. We used ten cone-shape samples ( $4 \times 4 \times 2 \mathrm{~mm})$. They were divided into 2 groups namely sisal nanofibers composite labeled as group A; Z350 XT as group B. Extracted premolar teeth were filled using samples with the total-etch adhesive (3M ESPE). The samples were investigated using a Scanning Electron Microscope (SEM) (JSM-6510LA) and their tensile strength was tested using a Universal Testing Machine (Vertical test ASL-S). The data were processed by Independent Sample T-Test analysis. Results: The mean of the tensile strength of group A was $4.39 \mathrm{MPa}$, and that of group B was $1.23 \mathrm{MPa}$. There was a significant difference $(p=0.004 ; p<0.05)$. SEM observation showed that there was no gap between the tooth structure with composite group A. Conclusion: Group A had better adhesion to tooth structure than group B and adequate tensile strength.
\end{abstract}

Keywords: Sisal nanofiber, dental restorative composite, tensile strength, microscopic adhesion

\section{INTRODUCTION}

Composite resin is one of the dental filling materials most commonly used because it has a high esthetic value relative to other dental filling materials [1]. Filler volume is known to affect the mechanical properties of composite resin. Hence, a higher filler volume will improve hardness, stiffness, strength, and fracture resistance [2]. Composite resin can be categorized into traditional, microfiller, hybrid, and nanofiller, depending on the type of the reinforcing materials used. The esthetic value of nanofiller composite resin is excellent, as it is easy to enhance and provides a brilliant dental esthetic restorative property [3][4].

In addition, composite resin is composed of the matrix, inorganic filler, and the agent of coupling. In the creation of composite resin physiology, the resin matrix found in the composite resins plays a major role. Inorganic filler is a substance that spreads within the resin matrix to reinforce it. Coupling agent performs a role in uniting an inorganic filler and a matrix. Apart from these three components, additional components are also available: activator- initiator, pigments, and ultraviolet absorbers [3]. The larger the volume of filler used in the composite resin, the higher the mechanical properties [5]. The filler percentage in the direct composite restorative material is commonly between $60-70 \%$ [6]. In addition, as these materials are hard and stable, the composite resin filler is developed from inorganic materials such as glass, zirconium, quartz and silica [7]. Nevertheless, inorganic materials have many drawbacks. One of which is that inorganic materials are unable to bind to organic matter, while tooth structure and adhesive materials consist of many organic materials. Natural fibers are a kind of organic material that is used as reinforcement materials for composite [8] [9].

Because of its high compressive strength, light load, and environmentally friendly relationship, natural fibers are expected to replace inorganic materials [10]. Sisal is one of the natural fibers that can be grown, as sisal fibers are hard fibers made from sisal plants (Agave sisalana). Sisal is one of the natural fibers mostly used and easily cultured. Sisal fibers have better bonds with polymer matrix resins than other fibers [11]. 
This paper contributed to new dental composite restorative material manufactured from sisal nanofibers as filler. This research focused on using sisal nanofibers as filler by combining the resin matrix to manufacture composite resin. The bond between the sisal nanofibers, resin matrix, and tooth structure can be considered as the $\mathrm{OH}$ group's chemical bond [8][12]. Thus, sisal nanofibers composite bonds with tooth structure tightly. In addition, tensile test observes the ability of adhesion between tooth structure and composite. Microscopic adhesion is one way of identification to watch the gap between teeth and composites which can be observed by Scanning Electron Microscope (SEM). Therefore, this research aimed to observed the adhesion between sisal nanofiber composite to tooth structure by SEM and tested by tensile strength.

\section{MATERIALS AND METHODS}

\subsection{Manufacturing Sisal Nanofiber}

The Indonesian Crops and Fiber Research Institute (Balittas), Malang, Indonesia, acquired the sisal fibers used in this research, referred to in Fig. 1. They were cut into fragments that were up to three grams in weight. During agitation with a magnetic stirrer, the fibers were then scrambled (alkalized) by soaking them in $\mathrm{NaOH}$ solution at $100^{\circ} \mathrm{C}$ for 120 minutes. This procedure was repeated three times. Before being bleached using a $\mathrm{NaOH}, \mathrm{H} 2 \mathrm{O} 2$, and distilled water solution, the fibers were then sifted and cleansed in distilled water. The bleaching process was conducted for two hours at $80^{\circ} \mathrm{C}$ while stirred with a magnetic stirrer. The bleaching process was then repeated four times. After each stage of the bleaching process, the fibers were sieved and rinsed in the distilled water. An ultrasonic system was used to process the sisal fibers (ColeParmer Ultrasonic, Model CP 505) following the bleaching phase (Flex-DryTM $\mu$ PMicroprocessor, FTS Systems, USA), to produce solid sisal nanofibers.

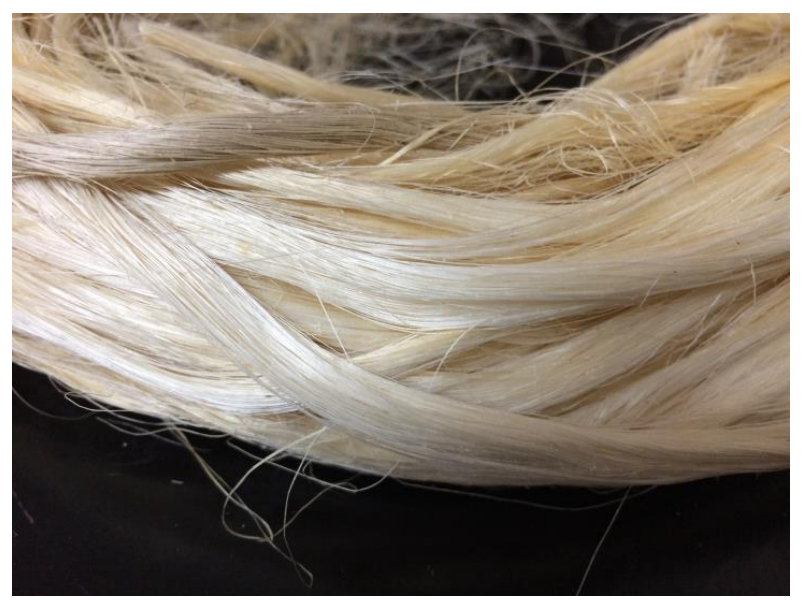

Figure 1 Sisal fibers [13]

\subsection{Manufacturing Sisal Nanofiber Dental Composite}

Subsequently, the solid sisal fibers were analyzed in a transmission electron microscope (TEM) to determine their size. In the next step, a digital scale weighted and separated the solid sisal nanofibers into samples weighing 0.003 grams. (60 percent volume of filler), to create a composite nano-sisal dough, each sample was combined with 0.5 grams of Bis-GMA (Bisphenol A dimethacrylate glycerolate, Sigma Aldrich), 0.02 grams of TEGDMA (Triethylene glycol dimethacrylate, Sigma Aldrich), 0.02 grams of UDMA (Diurethane dimethacrylate, Sigma Aldrich) and 0.09 grams of Champorquinone (Sigma Aldrich). This was then put into a cone-shaped mold ( 4 x 4 $x$ 2) $\mathrm{mm}$ by adhering to the ISO 4049 guidelines [14]. The products were combined using a stainless steel spatula on a glass tray. The samples were then irradiated for 40 seconds with a visible light (LED light-cure machine, LY- B200, S\&D Dental International Co., Ltd, Shanghai , China) before they were set up. These samples were then divided into two groups: a group with sisal nanofiber composite $60 \%$ and a group with nanofiller composite Z350XT. On the other hand, the composite nanofiller (Z350 XT, 3 M ESPE) to be used as the control (Group D) was collected from a plastic instrument tube, put into a mold, and polymerized for 40 seconds.

\subsection{Tensile Strength Test and Microscopic Adhesion Observations}

Table 1. Tensile strength of sisal nanofiber dental composite $60 \%$ and nanofiller Z350XT

\begin{tabular}{|c|c|c|}
\hline Sample & $\begin{array}{c}\text { Sisal Nanofiber } \\
\text { Composite 60\% (MPa) }\end{array}$ & $\begin{array}{c}\text { Nanofiller Z350XT } \\
(\mathrm{MPa})\end{array}$ \\
\hline 1 & 3.38 & 0.93 \\
\hline 2 & 6.62 & 2.78 \\
\hline 3 & 4.00 & 0.19 \\
\hline 4 & 4.44 & 0.25 \\
\hline 5 & 3.55 & 2.04 \\
\hline Mean & 4.39 & 1.23 \\
\hline
\end{tabular}

Extracted premolar teeth were prepared to class V (G. $\mathrm{V}$. Black classifications), then they were filled using the samples with a etch and rinse adhesive (Adper ${ }^{\mathrm{TM}}$ Single Bond 2 Adhesive, 3M ESPE). The adhesion of the two groups was then labelled at the center of the samples by a Universal Testing Machine (UTM, Mettler Toledo AL 204) to be tested for their tensile force. In the center of the UTM, each mold was mounted and the $1000 \mathrm{~N}$ load was utilized to the top of the sample with the vertical print location at 1 $\mathrm{mm}$ for a minute. The obtained data were in the type of a $\mathrm{N}$ 
unit, which was then translated to MPa using the following method (1): [15]

$$
\mathrm{Rc}=\frac{\mathrm{F}}{\mathrm{A}}
$$

Note:

Rc: Tensile strength (MPa)

\section{F: Maximum force $(\mathrm{N})$}

A: width of the sample base area $(\pi \mathrm{r} 2)(\mathrm{mm} 2)$

The tensile strength data obtained was evaluated by a parametric test, i.e; Independent Sample T-tests. Extracted premolar teeth were filled using the samples with the totaletch adhesive (3M ESPE). The samples were observed with a Scanning Electron Microscope (JSM-6510LA).

\section{RESULTS}

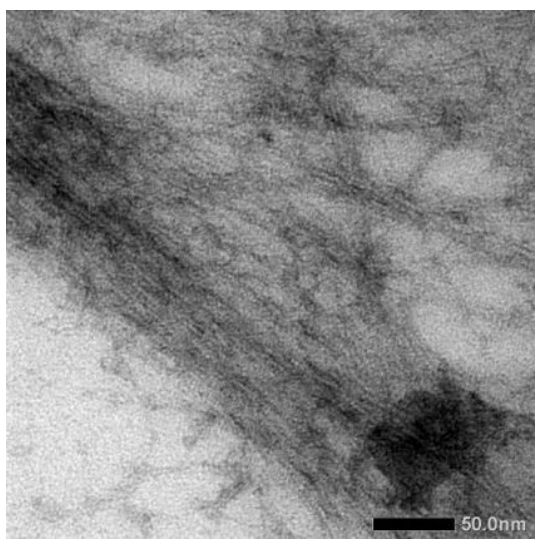

Figure 2 TEM Analysis Sisal Nanofibers (Magnification: $\mathrm{x} 10000)$

The TEM analysis showed that the sisal fibers were 11$31 \mathrm{~nm}$ in size, referring to Fig. 2. Solid nano-sisal fibers had been obtained. The results indicated that the mean tensile strength value was $4.39 \mathrm{Mpa}$ in the group of sisal nanofibers composite resins and $1.23 \mathrm{Mpa}$ in the group of nanofiller composite Z350 XT. A Shapiro Wilk test was then used to test the normality of the obtained data. The results of which showed that the data distribution was regular. The homogeneity of the data was then evaluated using a Levene test, whose results showed that the data variance was homogeneous.

Table 2. Tensile Summary of independent sample t-test

\begin{tabular}{|c|c|c|c|c|}
\hline & Group & N & Mean & Sig. \\
\hline $\begin{array}{c}\text { Tensile } \\
\text { strength }\end{array}$ & $\begin{array}{c}\text { Sisal } \\
\text { Nanofiber } \\
\text { Composite }\end{array}$ & 5 & 4.39 & 0.004 \\
\cline { 2 - 5 } & $\begin{array}{c}\text { Nanofiller } \\
\text { Z350XT }\end{array}$ & 5 & 1.23 & \\
\hline
\end{tabular}

Table I shows that the highest mean tensile strength was found in the group of sisal nanofiber composite resins. The highest tensile strength, therefore, was the sisal nanofiber composite. In addition, the p-value shown in Table II was $<0.004(p<0.05)$. This confirms that there was a significant difference in the tensile strength between $60 \%$ sisal nanofibers composite with nanofiller composite Z350XT. These results were similar to those observed with SEM on tooth extraction with $60 \%$ sisal nanofiber composite, and Z350XT nanofiller. Fig. 3 shows that there is no gap between the tooth with a sisal nanofiber composite. Fig. 4 shows a gap along the boundary between the tooth and the Z350XT composite resin density.

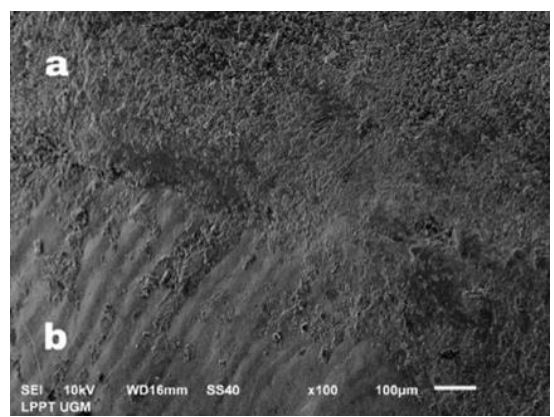

Figure 3 SEM Observation Sisal Nanofiber Composite with Tooth Structure

(a: Sisal

Nanofiber Composite; b: Tooth Structure)

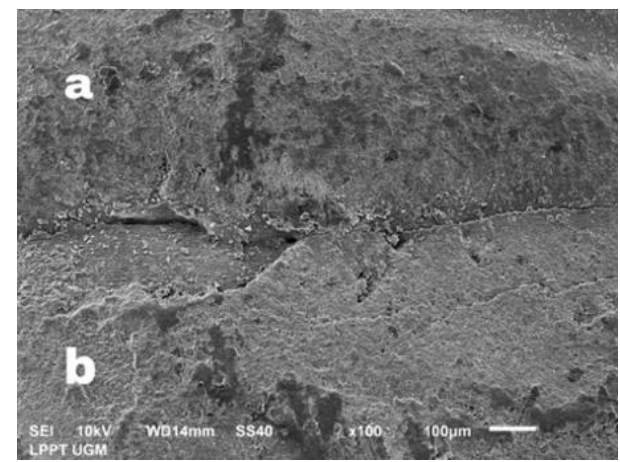

Figure 4 SEM Observation Sisal Nanofiller Composite Z350 XT with Tooth Structure (a:Nanofiller Composite Z350 XT; b: Tooth Structure)

\section{DISCUSSION}

The results showed that the group with sisal nanofiber composite had a greater tensile strength than the group with ESPE Z350 XT 3M nanofiller resin composite sample (Table I). This is due to using organic adhesive material for attaching sisal nanofibers and nanofiller Z350XT on the tooth structure. The components of adhesive materials for composite restorations are organic compounds in hydroxyethyl methacrylate (HEMA) monomers [16]. Nanosisal composite consists of organic material, while Z350XT nanofiller is a mixture of organic and inorganic materials. This way, the bond between the adhesive material with the sisal nanofiber composite was more robust and the 
tensile strength was also greater. That is in line with the results of some previous research, comparing the tensile strength between composite resin without sisal fiber and resin reinforced with sisal fibers, indicating that composite reinforced with sisal fibers experienced an increased tensile strength [17] .

Increasing bond resistance affects not only the adhesive structure but also the dental composite chemical composition. Differences in the chemical structures of composite resins may result in varying bond strengths during adhesive resin application. Different mechanical and physical properties of composite materials are influenced by differences in a resin matrix (monomers) and filler technology. The configuration of the monomer system defines the amount of bulk contraction that takes place during polymerization and the tension that results from this. The flowable materials studied have shown higher shrinkage strain and stress values. Filtek Z350 XT polymeric resin matrix consists of Bis-GMA, UDMA, TEGDMA, PEGDMA, and Bis-EMA.

A previous study stated that nanometric inorganic filler particles have a greater surface area for silane cover, allowing the silanization process to become more critical thus increasing the gap between the filler, the matrix, and tooth structure [18]. The results of the SEM analysis to the group of Z350 XT nanofiller (Fig. 4) have shown that inorganic fillers consisting of nanomers and nanocluster cannot perfectly bond with the resin matrix so there was a gap between the inorganic filler, resin matrix, and tooth structure.

Fig. 3 shows that there was no gap between the tooth with the sisal nanofiber composite. Nanosisal consists of hydroxyl group $(\mathrm{OH})$, and the tooth structure has hydroxyapatite $\mathrm{Ca}_{10}(\mathrm{PO} 4)_{6}(\mathrm{OH})_{2}$. They create chemical bond by hydrogen ionic molecules. Therefore, the sisal nanofiber composite had greater tensile strength and left no space with the tooth structure (by SEM observation) [19].

\section{CONCLUSION}

Sisal nanofibers composite can bond to tooth structure through a dentin bonding agent. Sisal nanofiber filler composite resin has a higher tensile strength than nanofiller composite resin. SEM observation shows that there is no gap between the tooth and a sisal nanofiber composite.

\section{ACKNOWLEDGMENTS}

The authors would like to thank Medical Molecular Therapy (MMT) for convenience laboratory. This research was supported by Lembaga Penelitian dan Pengabdian Masyarakat (LP3M) Universitas Muhammadiyah Yogyakarta (UMY).

\section{REFERENCES}

[1] R.E. Goldstein, S.J. Chu, E.A. Lee, C.F.J. Stappert, Esthetics in dentistry, Willey Blackwell, Hoboken, USA, 2018 , pp.147.
[2] K. Karthick, Shivakumar, Kailasam, Polymerization Shrinkage of Composites- A Review, JIADS, 2(2), 2011, pp.15-22.

[3] K.J. Anusavice, C. Shen, H.R. Rawls, Phillips' science of dental materials, $12^{\text {th }}$ ed, St. Louis, Elsevier Saunders, 2012, pp. 275-276.

[4] A.N. Khaled, Physical properties of dental resin nanocomposites, in: Thesis submitted to the University of Manchester for the degree of Master of Philosophy Manchester, University of Manchester, 2011, pp. 2627.

[5] S. Thomaidis, A. Kakaboura, W.D. Mueller, S. Zinelis, Mechanical properties of contemporary composite resins and their interrelations, Dent Mater. 2013, 29, pp.132-141.

[6] O.A. Adeleye, O.A. Fakinlede, J.T. Makinde, The effects of resin matrix composition, filler volume and particle size on the mechanical properties of dental resin composites, UNILAG Journal of Medicine, Science and Technology, 2016, 4(2), pp.58-70.

[7] H.R. Rezai, H.B. Rizi, M.M.R. Khamseh, A. Ochsner, A review on Dental Materials (Advanced Structured Materials), vol. 123, Springer, Gewerbestrasse, Switzerland, 2020, pp.137

[8] T. Sonar, S. Patil, V. Deshmukh, R. Acharya, Natural fiber reinforced polymer composite material- A review, IOSR Journal of Mechanical and Civil Engineering (IOSR-JMCE), 2015, pp.142-147.

[9] S.V. Joshi, L.T. Drzal, A.K. Mohanty, S. Arora, Are natural fiber composites environmentally superior to glass fiber reinforced composites?, Compos Part A Appl Sci Manuf., 2004, 35, pp, 371-376.

[10] N. Natarajan, S. Bharathidhasan, R. Thanigaivelan, P. Suresh, Sisal fiber / glass fiber hybrid nano composite: the tensile and compressive properties, in: $5^{\text {th }}$ International $\& 26^{\text {th }}$ All India Manufacturing Technology, Design and Research Conference, 2014, pp. 1-6.

[11] M. Boopalan, M.J. Umaphanty, P.A. Jenyfer, Comparative study on the mechanical properties of jute and sisal fiber reinforced polymer composites, Silicon, 2012, 4, pp.145-149.

[12] E.E.M. Ahmad, The influence of micro- and nano-sisal fibers on the morphology and properties of different polymers, in: Thesis submitted to Faculty of Natural Science for degree of doctor of philosophy, 2011, pp. 60 .

[13] D. A. Nugroho, Widjijono, Nuryono, W. Asmara, Wijayanti, Ardianata, Effect of filler volume of nanosisal in compressive strength of composite resin, 
Dental Journal (Majalah Kedokteran Gigi), 2017, 50(4), pp. 183-187.

[14] International Organization of Standardization (ISO). Dentistry - Polymer-based restorative materials. 4th edition, 2009: 4049.

[15] V.H. Grandi, S. B. Berger, A.P.P. Fugolin, A. GoniniJúnior, M. B. Lopes, S. Consani, R.D. Guiraldo, Microtensile Bond Strength and Microhardness of Composite Resin Restorations Using a Sonic-Resin Placement System, Brazilian Dental Journal, 2017, 28(5), pp.618-623.

[16] H.N. Lim, S.H. Kim, B. Yu, Y.K. Lee, Influence of HEMA content on the mechanical and bonding properties of experimental HEMA added glass ionomer cement, J Appl Oral Sci, 2009, 17(4), pp. 340-349.

[17] R.S. Rana, A. Kumre, S. Rana, R. Purohit, Characterization of properties of epoxy sisal / glass fiber reinforced hybrid composite, Proceedings of Materials Today, 2017, pp.5445-5451.

[18] S. Somashekar, G.C. Shanthakumar, Effect of alkali treatment on mechanical properties of sisal-reinforced epoxy polymer matrix composite, Int. J. Mech. Eng and Rob. Res., 2014, 3(4), pp. 441-450.

[19] K. Ilomaki, Adhesion between natural fiber and thermosets, in: Thesis submitted to the Tampere University of Technology for the degree of Master of Science, 2012, pp. 37. 